\title{
Assessment of activity levels for CYP2D6*1, CYP2D6*2, and CYP2D6*41 genes by population pharmacokinetics of dextromethorphan
}

\author{
Abduljalil, K ; Frank, D ; Gaedigk, A ; Klaassen, T ; Tomalik-Scharte, D ; Jetter, A ; Jaehde, U ; \\ Kirchheiner, J ; Fuhr, U
}

\begin{abstract}
The pharmacokinetics of dextromethorphan (DM) is markedly influenced by cytochrome P450 2D6 (CYP2D6) enzyme polymorphisms. The aim of this study was to quantify the effects of the CYP2D6*1, ${ }^{*} 2$, and $* 41$ variants on DM metabolism in vivo and to identify other sources of pharmacokinetic variability. Concentrations of DM and dextrorphan (DO) in plasma and urine were evaluated in 36 healthy Caucasian men. These volunteers participated in three clinical studies and received a single oral dose of $30 \mathrm{mg}$ DM-HBr. Data were modeled simultaneously using the population pharmacokinetics NONMEM software. A five-compartment model adequately described the data. The activity levels of the alleles assessed differed significantly. The clearance attributable to an individual CYP2D6*1 copy was 2.5-fold higher as compared with CYP2D6*2 (5,010 vs. 2,020 l/h), whereas the metabolic activity of CYP2D6*41 was very low $(85 \mathrm{l} / \mathrm{h})$. Urinary $\mathrm{pH}$ was confirmed as a significant covariate for DM renal clearance. These results refine genotype-based predictions of pharmacokinetics for DM and presumably for other CYP2D6 substrates as well.
\end{abstract}

DOI: https://doi.org/10.1038/clpt.2010.137

Posted at the Zurich Open Repository and Archive, University of Zurich ZORA URL: https://doi.org/10.5167/uzh-38656

Journal Article

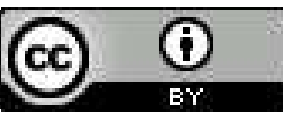

The following work is licensed under a Creative Commons: Attribution 3.0 Unported (CC BY 3.0) License.

Originally published at:

Abduljalil, K; Frank, D; Gaedigk, A; Klaassen, T; Tomalik-Scharte, D; Jetter, A; Jaehde, U; Kirchheiner, J; Fuhr, U (2010). Assessment of activity levels for CYP2D6*1, CYP2D6*2, and CYP2D6*41 genes by population pharmacokinetics of dextromethorphan. Clinical Pharmacology and Therapeutics, 88(5):643651.

DOI: https://doi.org/10.1038/clpt.2010.137 
ACTIVITY ASSESSMENT FOR $C Y P 2 D 6 * 1, C Y P 2 D 6 * 2$ AND $C Y P 2 D 6 * 41$ GENES BY POPULATION PHARMACOKINETICS OF DEXTROMETHORPHAN

Khaled Abduljalil ${ }^{1,2}$, Dorothee Frank ${ }^{1}$, Andrea Gaedigk ${ }^{3}$, Tobias Klaassen ${ }^{1}$, Dorota Tomalik-

Scharte $^{1}$, Alexander Jetter ${ }^{1,4}$, Ulrich Jaehde ${ }^{5}$, Julia Kirchheiner ${ }^{6}$, Uwe Fuhr ${ }^{1}$

${ }^{1}$ Department of Pharmacology, Clinical Pharmacology Unit, University Hospital, University of Cologne, Germany

${ }^{2}$ SimCYP Limited, Sheffield, United Kingdom

${ }^{3}$ Division of Developmental Pharmacology \& Experimental Therapeutics, The Children's Mercy Hospital and Clinics, Kansas City, USA

${ }^{4}$ Division of Clinical Pharmacology and Toxicology, University Hospital Zurich, Zürich, Switzerland

${ }^{5}$ Department of Clinical Pharmacy, Pharmaceutical Faculty, University Bonn, Germany

${ }^{6}$ Department of Pharmacology of Natural Products \& Clinical Pharmacology, University of Ulm, Germany

\section{Correspondence:}

Prof. Dr. med. Uwe Fuhr, Department of Pharmacology, Clinical Pharmacology, University of Cologne, Gleueler Straße 24, 50931 Köln, Germany;

Fax: +49-221-478-7011, phone: +49-221-478-5230, e-mail: uwe.fuhr@uk-koeln.de

Word counts: abstract, 150; introduction, 793; manuscript as a whole, 3998

The manuscript contains 45 references, 4 figures, and 3 tables.

Key words: dextromethorphan, dextrorphan, CYP2D6, genetic polymorphism, population pharmacokinetics 


\begin{abstract}
Dextromethorphan pharmacokinetics is markedly influenced by CYP2D6 enzyme polymorphisms. The aim of this study was to quantify the effect of the $C Y P 2 D 6 * 1, * 2$ and *41 variants on dextromethorphan metabolism in vivo and to identify other sources of pharmacokinetic variability. Plasma and urine concentrations of dextromethorphan and dextrorphan were evaluated from 36 healthy Caucasian males. These volunteers participated in three clinical studies and received a single oral dose of $30 \mathrm{mg}$ dextromethorphan- $\mathrm{HBr}$. Data were modelled simultaneously using the population pharmacokinetic NONMEM software. A five-compartment model adequately described the data. Activities of the alleles assessed differed significantly. The clearance attributable to an individual $C Y P 2 D 6 * 1$ copy was 2.5fold higher compared to CYP2D6*2 (5010 vs $2020 \mathrm{~L} / \mathrm{h})$ while the metabolic activity for CYP2D6*41 was very low $(85 \mathrm{~L} / \mathrm{h})$. Urinary $\mathrm{pH}$ was confirmed as a significant covariate for dextromethorphan renal clearance. These results refine genotype-based prediction of pharmacokinetics for dextromethorphan and presumably other CYP2D6 substrates.
\end{abstract}




\section{Introduction}

Dextromethorphan (DM) is an antitussive drug with rapid absorption from the gastrointestinal tract $\left(\mathrm{k}_{\mathrm{a}}=2.6+/-0.9 \mathrm{~h}^{-1}\right)$ after oral administration and a large central volume of distribution $961 \mathrm{~L}$ ranging from 585 to 1292 litres.(1) DM undergoes rapid and extensive first-pass metabolism mainly by CYP2D6 with an oral bioavailability ranging from $1 \%$ to $2 \%$ and about $80 \%$ in extensive and poor CYP2D6 metabolizer subjects, respectively(2) Its intrinsic hepatic clearance was about 22L/h and $4737 \mathrm{~L} / \mathrm{h}$ in respective CYP2D6 metabolizer groupss,.(2) In another study a value of $1280 \pm 483 \mathrm{~L} / \mathrm{h}$ for its apparent clearance has been reported for CYP2D6 extensive metabolizers.(3) Primary metabolic steps include formation of dextrorphan (DO) mainly by CYP2D6 and of 3-methoxymorphinan by CYP3A enzymes. Both are further metabolized to 3-hydroxymorphinan by CYP3A4 and CYP2D6, respectively. $(4,5)$ The dominating metabolic pathway in the majority of the population is the conversion of DM to DO by CYP2D6, contributing to more than $80 \%$ to the formation of DO. $(1,6)$ The selectivity of DO formation via CYP2D6, in addition to its favourable safety and availability, has made DM a probe of choice for CYP2D6 phenotyping.(7)

CYP2D6 is a highly polymorphic gene with more than 100 known allelic variants (March 15, 2010; http://www.cypalleles.ki.se/cyp2d6.htm). Because the overall disposition of DM is highly dependent on CYP2D6 activity, these polymorphisms are the main source for the wide interindividual variation in its plasma levels and response. $(8,9)$ For other CYP2D6 substrates such as antidepressants and antipsychotic drugs such variability can lead to failure of treatment in carriers of alleles encoding very high CYP2D6 activity or may expose individuals carrying alleles conferring no or low activity to a high risk of toxicity.(10, 11) Conversely, for some opioids such as dihydrocodeine, codeine and tramadol, where a highly active metabolite is formed by CYP2D6, therapeutic failure may be associated with low activity genotypes and toxicity with genotypes resulting in high enzymatic activity.(12, 13)

As a prerequisite to personalize therapy with CYP2D6 substrates, different proposals have been made to establish simple useful systems for the prediction of CYP2D6 phenotype based on CYP2D6 genotype.(14) Such predictions suffer from potential pitfalls depending on the correctness of underlying assumptions. The classical procedure divided populations based on the urinary metabolic ratio of DO over DM and an arbitrary "cut-off" value, i.e. antimode, into poor and extensive metabolizers.(15) While subjects with two non-functional alleles represent the poor metabolizer group, it is difficult to precisely predict the phenotype of individuals carrying combinations of functional and reduced function alleles. Furthermore, 
wide variability in CYP2D6 activity is not only observed between subjects with different functional genotypes, but is also rather the rule than the exception among subjects within a genotype group.(16) Attempts to better classify especially those subjects carrying gene duplications and reduced function alleles, ultra-rapid and intermediate metabolizers subgroups have been introduced creating a polymodal population distribution.(17)

Another system called semi-quantitative scoring system defining categories for CYP2D6 alleles has been developed(18) which assigns scores to each allele ( 1 for fully functional alleles, 0.5 for reduced activity functional alleles, and zero for non-functional alleles) and uses these 'gene doses' as an indicator for phenotype. Another recent scoring system, the so-called activity score system, also assigns values to individual CYP2D6 alleles and utilizes their sum as a surrogate to predict phenotype.(8) Because the model did not improve when assigning values of 0.25 and 0.75 to alleles perceived to confer slight and substantial reduction in activity, the simplest model using values of 1 for fully functional, 0.5 for all reduced activity, and 0 for non-functional alleles, respectively, was chosen. In an effort to better describe the alleles carrying functional gene duplications such as $C Y P 2 D 6 * 1 x N$ or $* 2 x N$, the value of the allele was doubled, i.e. a value of 2 was assigned to $C Y P 2 D 6^{*} 1 x N$. Although these classification systems have improved phenotype prediction, considerable variability within score groups persists.

By definition, these scoring systems are valid for non-functional alleles such as $C Y P 2 D 6 * 3$ and $* 4$, but the simplifying assumption that fully functional alleles such as $C Y P 2 D 6 * 1$ and $* 2$ have identical activity enzymes can be challenged, as well as the allocation of a value of 0.5 to any low activity allele. Indeed, several mechanisms including differences in splicing and other reasons for different expression levels, enzyme stability, and/or substrate specific enzyme kinetics may cause net differences for in vivo substrate turnover between individual functional CYP2D6 variants.

Thus, there is a need to precisely quantify the in vivo activity associated with CYP2D6 allelic variants and genotypes to better predict phenotype from genotype data. Such information will ultimately be useful for clinical decision making in respect to drug selection and dose adjustment. In the present study we assessed the activity of individual CYP2D6 alleles with regard to the clearance of DM to DO, using a population pharmacokinetic approach.

\section{Results}


A total number of 537 plasma samples and 136 urine samples from 36 healthy Caucasian men obtained after oral administration of a $30 \mathrm{mg} \mathrm{DM}-\mathrm{HBr}$ dose were analysed for $\mathrm{DM}$ and $\mathrm{DO}$ concentrations in this study. Demographic and CYP2D6 genetic characteristics of these volunteers are given in Table 1 and 2, respectively.

As expected, we observed large interindividual differences in the time-concentration profiles within the data set, with the highest variability for DM. DM initial plasma concentrations decreased rapidly in many, but not all, individuals (within the first 5 hours after dosing) reflecting the known variability in drug clearance. DO plasma concentrations appeared in many individuals earlier than the parent drug, supporting the importance of first-pass metabolism.

Modelling all data with the basic structure 4-compartment model (see Methods section) was not sufficient to describe the data, with misspecifications especially for parent concentrations in plasma. Addition of a peripheral compartment for DM was associated with a significant drop in the objective function value $(\Delta=-114)$. Based on individual and population predictions, this model was still unable to account for the early appearance of DO in plasma. Therefore, other models $(19,20)$ that take the first pass metabolism into account were tested. These models were stepwise simplified or extended for modelling the available data. A hypothetical metabolism compartment was added assumed to be in rapid equilibrium with the central compartment of the parent drug, with all metabolic steps taking place in this compartment. After administration of the drug, it was assumed that the drug goes from the absorption site to the metabolism compartment before reaching the plasma (for specifications, see appendix A). This model was associated with a profound drop in the objective function value $(\Delta=-324)$. Inclusion of a lag-time parameter led also to further significant drop in the objective function $(\Delta=-45)$.

With respect to identification of covariates, as expected CYP2D6 genotype had a major impact on the metabolic clearance $(\Delta=-532)$. About $55 \%$ of the interindividual variability (CV \%) in DM metabolic clearance, CL23, was explained by addition of CYP2D6 genotype as a covariate. Inclusion of urine $\mathrm{pH}$ values as a covariate on renal clearance of DM also resulted in a significant drop in the objective function value $(\Delta=-105)$. The best form of this relationship was that included in the final model and is described by the following empirical equation:

$$
\theta_{\mathrm{PV}}=\theta_{\mathrm{TV}} \cdot(5.7 / \mathrm{UpH})^{\theta \mathrm{s}}
$$


where $\theta_{\mathrm{PV}}$ is the individual value of renal clearance, $\theta_{\mathrm{TV}}$ is the population value of renal clearance, the value 5.7 represent a published mean of urine $\mathrm{pH}$ in humans(21), $\mathrm{UpH}$ is the measured individual urine $\mathrm{pH}$ at each collection period, and $\theta \mathrm{s}$ is the shape parameter which explains the change in renal clearance in terms of change in urine $\mathrm{pH}$. Using the non-ionized fraction of DM calculated according the Henderson-Hasselbalch equation as a covariate was inferior to this empirical equation. Including an effect of urine $\mathrm{pH}$ on renal clearance of DO did neither improve model fitting nor led to a decrease in the OFV. The model also identified age as important covariate. Age contributed to interindividual variability in the apparent volume of distribution of DO $(\Delta=-21.9)$ and the clearance of DO to other species, $\mathrm{CL}_{30},(\Delta=-$ 5.8). This covariate was modelled according to the relationship:

$$
\theta_{\mathrm{PV}}=\theta_{\mathrm{TV}} \cdot \operatorname{EXP}\left(\theta_{\mathrm{AGE}} \cdot(\mathrm{AGE}-27)\right)
$$

where $\theta_{\mathrm{PV}}$ is the population value of the model parameter, $\theta_{\mathrm{TV}}$ is the typical value in an individual with age of 27 years old (the median age in this study). $\theta_{\mathrm{AGE}}$ is the fractional change in $\theta_{\mathrm{PV}}$ per year different from 27 years of age. None of other apparent volumes of distribution, clearance, or inter-compartmental clearance parameters has been found to be influenced by age in this study. Neither body weight nor height was found to significantly contribute to model disposition parameters. Plasma data were best fitted if combined additive and proportional error terms were used, while urine data were best fitted with proportional error terms. The blueprint of the final model is shown in Figure 1.

Final pharmacokinetic parameter estimates with $95 \%$ confidence intervals are shown in Table 3. The apparent metabolic clearance $\left(\mathrm{CL}_{23}\right)$ estimate ranged from 10 to $10030 \mathrm{~L} / \mathrm{h}$ in this population. The fraction of the clearance attributable to a $C Y P 2 D 6 * 1$ copy was on average 2.5-fold greater than that for $C Y P 2 D 6 * 2$. $C Y P 2 D 6 * 41$ related clearance was lowest: the point estimates per copy were $5010 \mathrm{~L} / \mathrm{h}, 2020 \mathrm{~L} / \mathrm{h}$ and $85 \mathrm{~L} / \mathrm{h}$ for $C Y P 2 D 6 * 1$, *2 and *41, respectively.

Diagnostic plots of the final model are given in Figure 2, indicating model adequacy. The $5^{\text {th }}$, $50^{\text {th }}$ and $95^{\text {th }}$ percentiles from simulated data, based on the final model estimates, are shown in Figure 3. Simulated time courses of plasma concentrations and cumulative amounts excreted in urine for subjects who are homozygous for a given allele, i.e. $C Y P 2 D 6 * 1 / * 1$, *2/*2, etc, are given in figure 4. The expected values of standard CYP2D6 phenotypic metrics, i.e. metabolic ratios of DM over DO at $3 \mathrm{~h}$ in plasma and $0-8 \mathrm{~h}$ in urine, were 0.12 and 0.015 for $C Y P 2 D 6 * 1 / * 1$, 0.28 and 0.04 for $C Y P 2 D 6 * 2 / * 2,5.0$ and 0.079 for $C Y P 2 D 6 * 41 / * 41$, and 90.9 and 14.3 for CYP2D6*4/*4 carriers (simulated for a 27 -years old male having a urine $\mathrm{pH}$ of 5.7 ). 


\section{Discussion}

The main objective of this study was to quantify the metabolic activity attributable to frequent individual CYP2D6 alleles using DM as a probe drug. The mean CYP2D6 mediated clearance $\mathrm{CL}_{\text {CYP2D6 }}$ is estimated as $15030 \mathrm{~L} / \mathrm{h}$ in subjects genotyped as CYP2D6 *1/*1x2, whereas it is $170 \mathrm{~L} / \mathrm{h}$ in subjects who carry two $C Y P 2 D 6 * 41$ alleles, and zero for subjects with genotypes comprising two non-functional alleles. The results suggest that quantitative differences in DM based phenotyping metrics between CYP2D6 genotypes are similar to the differences in enzyme activity, despite additional processes with impact on DM pharmacokinetics (see Table 3).

Based on the final model estimates, the activity for the $C Y P 2 D 6^{*} 1$ allele with respect to formation of $\mathrm{DO}$ in vivo is about 2.5 -fold higher compared to that seen for the CYP2D6*2 allele. The CYP2D6.2 protein differs from the CYP2D6.1 protein in two amino acids (R296C and S486T) (http://www.cypalleles.ki.se/cyp2d6.htm), while there is no evidence that the CYP2D6*2 allele differs from the $* 1$ allele with respect to expression levels. Key substrate binding sites of CYP2D6 include D301, F120, F483 and F481.(22) However, both positions 296 and 486 are supposed to be part of the substrate recognition site regions(23), and especially replacement of the large positively charged arginine by cysteine close to position 301 may well modify substrate binding but not profoundly change catalytic properties. Indeed, early reports by Sachse et al(17) showed that presence of the CYP2D6*2 allele was related to a slightly reduced enzyme activity as determined by urinary DM and/or debrisoquine phenotyping metrics. Both $\mathrm{DM}$ and pinoline intrinsic clearance for the respective O-demethylation in enzyme variants purified after expression using a baculovirusmediated system were only a fifth for CYP2D6.2 compared to CYP2D6.1.(24, 25) Differences were smaller but in the same direction for other reactions: DM N-demethylation, 0.77-fold; codeine O-demethylation, 0.35-fold; and fluoxetine N-demethylation, 0.26fold.(24) Intrinsic clearance for CYP2D6.2 expressed in Saccharomyces cerevisiae compared to CYP2D6.1 was also about 0.5 -fold lower for several progesterone hydroxylation pathways and 0.23 -fold lower for dopamine formation from D-tyramine.(26) The respective activity ratio of CYP2D6.2 over CYP2D6.1 expressed in yeast was 0.44-fold for DM Odemethylation and 0.74 -fold lower for bufurolol 1'-hydroxylation, while there were no differences with regard to metabolism of debrisoquine or metoprolol.(27) In a COS-7 expression system, CYP2D6.2 reached 0.71-fold and 0.72-fold activity relative to CYP2D6.1 for DM O-demethylation and bufuralol hydroxylation.(28) In summary, on an average CYP2D6.2 is approximately half active than CYP2D6.1. Whether the reported differences in 
this ratio between substrates in the in vitro assays are real or rather reflect the notorious problems in reproducibility of in vitro enzyme kinetic parameters(29) remains to be assessed in detail by clinical studies. Indeed, differences in urinary DM/DO metabolic ratios in a Gabonese population(30) showed the same difference between $C Y P 2 D 6 * 1$ and $* 2$ carriers as observed here.

Furthermore, this study shows that the metabolic clearance of DM conveyed by CYP2D6*41 is markedly less than that of $C Y P 2 D 6 * 1$. It is well-known that the activity for $C Y P 2 D 6^{*} 41$ is lower when compared to $C Y P 2 D 6 * 1$ and $* 2$. CYP2D6*41 codes for the lower activity CYP2D6.2 protein and in addition has a lower level of expression, as shown by 2- to 5-fold lower levels of CYP2D6 mRNA containing exon 6, apoprotein and enzyme activity in mechanistic studies.(31) When comparing to individuals with only one functional *1 allele, there was a 0.27 -fold lower mean enzyme activity in individuals with one functional $* 41$ allele as quantified by the sparteine metabolic ratio (data taken from graph) (32). This is the first quantitative estimate for activity attributable to CYP2D6*41 in vivo based on DM Odemethylation. The extent of the difference $(0.017$-fold) is approximately one order of magnitude higher than expected from previous information and needs to be confirmed in larger groups with this genotype.

The finding that the $C Y P 2 D 6^{*} 1$ allele is associated with an about 2.5 -fold higher activity with dextromethorphan compared to $C Y P 2 D 6 * 2$ would suggest that different activity values need to be assigned to these alleles in scoring systems. Both the activity score(8) and semiquantitative scoring (18) systems assumed similar activity for the $C Y P 2 D 6 * 1$ and $* 2$ alleles. To reflect reduced activity, these systems $(8,18)$ assigned a value of 0.5 to the $C Y P 2 D 6 * 41$ allele. Based on the results presented here, clearance for $C Y P 2 D 6 * 41$ is approximately 60fold reduced in comparison to $C Y P 2 D 6 * 1$. Consequently scoring values of $1,0.4$ and 0.017 should be assigned to $C Y P 2 D 6 * 1, * 2$ and $* 41$, respectively to more accurately reflect their activity. Using the respective final parameter estimates, DM pharmacokinetics for various genotypes were simulated (Figure 4). Similar genotype specific predictions can be made for other CYP2D6 substrates. Such predictions, however, may need to be modified, since previous studies demonstrated that protein specific activity of cytochrome P450 enzymes including CYP2D6 is in part substrate dependent. $(11,33,34)$

The final pharmacokinetic model describes the pharmacokinetic profiles of DM and its major metabolite adequately. In this model, inclusion of the hypothetical metabolism compartment 
was able to explain the appearance of DO in plasma before DM. The presented model shares some features with previously reported models that have been successfully applied to describe first-pass metabolism. $(1,20)$ The specific features in our model are that, (i) activity of active alleles of $C Y P 2 D 6$ were estimated separately, (ii) urinary data of both parent and metabolite were included in the model and simultaneously evaluated with plasma data; (iii) the impact of urine $\mathrm{pH}$ on DM clearance was quantified; (iv) it can be extended to estimate the activity of other additional alleles such as $* 9, * 10$, and $* 17$ alleles in other data sets. These features increase applicability of the model, while its clinical implications remain to be ascertained.

Our findings are in line with published data assuming a two-compartment model for DM (1, 35) and one-compartment models for DO.(1) The absorption rate constant $\left(\mathrm{h}^{-1}\right)$ estimate is about 0.25 , which lies between previously reported values of $2.6 \mathrm{~h}^{-1}$ and $0.1 \mathrm{~h}^{-1} .(1,36)$ The lag time was estimated to be $0.31 \mathrm{~h}$, which also lies between previously reported values $0.8 \mathrm{~h}$ and 0.087 h. $(1,35)$ The model estimates for the apparent central and peripheral volumes of distribution of DM in this study are smaller at $648 \mathrm{~L}$ and $1560 \mathrm{~L}$ compared with the previously reported values of $961 \mathrm{~L}$ and $1951 \mathrm{~L}$.(1) The volume of distribution of DO with $419 \mathrm{~L}$ is smaller than the reported value of $650 \mathrm{~L}$ (37) and $3776 \mathrm{~L}(1)$, but higher than $109 \mathrm{~L}$ reported by others. (38) Urine $\mathrm{pH}$ plays a significant role as a covariate and explains part of the variability seen in DM metabolic ratios. This is in agreement with a previous study describing an approximate 20 -fold variation in the urinary metabolic ratio due to urinary pH.(39) Taken together, these comparisons suggest that our model is valid.

The goodness-of-fit plots (Figure 2) show a possible overestimation of some DM and DO concentrations in plasma/urine, both due to model misspecification which is a semimechanistic rather than a fully mechanistic model. This may be explained by the existence of other sources of variability that were not taken into account in the final model. Possible sources could be the interindividual variability in CYP3A activity, incomplete description of the first pass metabolism such as the formation of methoxymorphinan from DM, the lack of modeling the metabolic fate of DO, the possible contribution of glucuronidation, and interstudy variability and lastly, the possibility that further sequence variations were present in addition to those covered in the genotype analysis. The interaction between the final model and the study design can be seen from the simulated predictive check plots. Generally inadequately fitted concentrations form only a negligible fraction of the whole data set. 
In conclusion, the final population model adequately described DM pharmacokinetics in healthy Caucasian men. The results confirmed that individual CYP2D6 genotype and to a lesser degree urine $\mathrm{pH}$ contribute to the variability in pharmacokinetic profiles of DM. The estimated quantitative differences in the metabolic capacity attributable to copies of individual CYP2D6 genes including $* 1, * 2$ and $* 41$ suggest that existing scoring systems to predict CYP2D6 activity from CYP2D6 genotype need to be refined. To which extent the observed activity differences between functional alleles for DM as a substrate are the same for other substrates remains to be assessed. (40) 


\section{Methods}

Study design

Data derived from 36 healthy Caucasian male volunteers who participated in 3 cocktail interaction studies were used for this evaluation; $n=15$ from study $A, n=10$ from study $B$, and $\mathrm{n}=11$ from study C. $(41,42)$ The data evaluated in this study were taken from the respective reference period where each subject received a single oral dose of $30 \mathrm{mg}$ DM hydrobromide (one capsule of Hustenstiller-ratiopharm, Ratiopharm, Ulm, Germany). Subjects eligible for inclusion in the analysis were carriers of one, two or a combination of the following allelic variants: $C Y P 2 D 6 * 1, * 1 x N, * 2, * 2 x N, * 3, * 4, * 4 x N, * 6, * 41$ or $* 41 x N$. Details of demographic data of the 36 subjects are shown in Table 1.

Blood samples were collected for quantification of DM and DO as follows: study A immediately before administration and $0.17,0.5,0.75,1.0,1.33,2.0,3.15,4.25,5.25,6.0,8.0$, 10.0, 11.95, 14.0, 24.0 $\mathrm{h}$ after dosing; study B immediately before administration and 0.17, $0.33,0.50,1.0,1.33,1.67,2.0,2.5,3.25,3.95,4.5,5.25,7.00,10.00,12.0,16.0,24.0 \mathrm{~h}$ after dosing; study C immediately before administration and $0.17,0.33,0.50,0.75,1.00,1.33$, 1.67, 2.0, 2.5, 3.25, 3.95, 4.13, 4.25, 4.5, 4.75, 5.0, 5.5, 6.5, 8.0, 10.0, $12.0 \mathrm{~h}$ after dosing.

To determine the urinary metabolic ratio of DM to DO, urine samples were collected periodically and their volumes and $\mathrm{pH}$ values measured of each collection period. Urine sampling schedules were: study A immediately before administration and 0-2, 2-4, 4-6, 6-8, 8-12, 12-16 und 16-24 h after dosing; study B immediately before administration and, 0-6 und 6-12 h after dosing; study $\mathrm{C}$ immediately before administration and, 0-2, 2-4, 4-6, 6-8, 8-12 h after dosing.

\section{Quantification of DM and DO}

Plasma and urine samples were analyzed according to a previously published validated LCMS/MS method.(43) Urine samples were treated with $\beta$-glucuronidase for cleavage of the DO glucuronides before measurement. The lower limits of quantification were $0.103 \mathrm{ng} / \mathrm{mL}$ for $\mathrm{DM}$ and $0.101 \mathrm{ng} / \mathrm{mL}$ for DO. Precision ranged from 3.2 to $7.8 \%$ for $\mathrm{DM}$, and from 4.7 to $9.2 \%$ for DO, while accuracy was $101.8-102.9 \%$, and $97.4-99.5 \%$ for DM and DO, respectively.

\section{Genotyping}

Genotyping was performed essentially as described earlier in detail.(8) Briefly, a $6.6 \mathrm{~kb}$ long CYP2D6-specific PCR product was generated and subsequently used as a template to 
determine the presence of allele-identifying SNPs. Gene duplications and the $C Y P 2 D 6 * 5$ gene deletion were also determined by long-range PCR (44)

\section{Population pharmacokinetic modelling}

All plasma and urine-derived data points for DM and DO were analysed simultaneously using the nonlinear mixed-effect software in NONMEM version VI (Globomax, LLC, Hanover, MD, USA). The analysis was performed using the first-order conditional estimation method with interactions (FOCE INTER). Models were specified in set of differential equations using the ADVAN6 subroutine and were parameterized for disposition kinetics using apparent clearance and volume of distribution terms.

The activity of the non-functional $C Y P 2 D 6 * 4$, *3 and $* 6$, or null enzyme variants was set to zero as these alleles carry inactivating sequence variations (http://www.cypalleles.ki.se/cyp2d6.htm). Clearance of DM in individuals with CYP2D6*null/*null genotypes was assumed to reflect non-CYP2D6-mediated clearance. Hence, the study evaluated the activity of alleles containing $C Y P 2 D 6 * 1, * 2$ and $* 41$ gene copies, which have been recognized as true variants influencing DM metabolism activity in vivo.(17, 32) In addition to $C Y P 2 D 6$ polymorphisms, age, urine $\mathrm{pH}$, and body weight were considered as covariates during model building. An allometric model was tested for weight, while exponential and combined models were tested to centre the age effect to the mean or the median age values.(45) Different relationships were tested to explore the effect of urine $\mathrm{pH}$ on renal clearances of DM and DO. Covariates were included in the model in a forward stepwise manner and backwards removed starting with the covariate that resulted in most reduction in the objective function value (OFV). This procedure was repeated until no significant drop was obtained in OFV.

As a starting point for the model building, a four-compartment open model was tested to describe the entire data set. Each compartment represents each site of measurement (i.e., two compartments each [plasma and urine] for DM data and two compartments for DO data). A first-order absorption process with and without a lag time was explored. Disposition processes for both substances were assumed to follow linear kinetics. For the purpose of the semimechanistic model, DM was assumed to be converted entirely to DO. This metabolic clearance was described as follows: $\mathrm{CL}_{\mathrm{m}}=\mathrm{CL}_{\mathrm{b}}+\mathrm{CL}_{\mathrm{CYP} 2 \mathrm{D} 6}$ where $C L_{\mathrm{m}}$ is the total apparent clearance of DM describing the biotransformation of $\mathrm{DM}$ to $\mathrm{DO}, \mathrm{CL}_{\mathrm{b}}$ is the basic value for DM metabolic clearance that is not subject to CYP2D6 activity, $\mathrm{CL}_{\mathrm{CYP} 2 \mathrm{D} 6}$ is the metabolic 
clearance due to CYP2D6 activity. $\mathrm{CL}_{\mathrm{CYP} 2 \mathrm{D} 6}=\mathrm{n} *_{1} * \mathrm{CL} *_{1}+\mathrm{n}_{2} * \mathrm{CL} *_{2}+\mathrm{n} *_{41} * \mathrm{CL} *_{41}$, where $\mathrm{n}_{*_{\mathrm{x}}}$ and $C \mathrm{~L}_{\mathrm{x}}$, are the number of gene copies observed and metabolic clearance values attributable to the respective gene. This model was selected as a basic structural model for further model building activities.

An exponential interindividual variability model was included for all model parameters forward and backward step by step interchangeably. Four residual-error models were added, one for each data type (i.e., a separate residual-error model for plasma parent data, another for plasma metabolite data etc.). Each residual error model was built up using an additive model, a proportional model, or a combination of both.

Model derivation and justification was guided by (i) the difference in the objective function value $(\triangle \mathrm{OFV})$ generated via NONMEM, a $\triangle \mathrm{OFV}$ of 3.84 (approximate $\chi^{2}$-distribution) for an additional parameter was used to determine statistical significance $(P<0.05)$ of the difference between any two models, (ii) visual inspection of goodness-of-fit plots, as well as (iii) physiological plausibility and statistical precision of model parameter estimates. The final model performance was also justified by simulating plasma and urine concentration time profiles for 1000 subjects having the observed CYP2D6 allele combinations and visualized using the Active Perl program (Active Perl, version 5.10.0; ActiveState, Vancouver, Canada). 


\section{Appendix}

The differential equations specifying the model shown in Figure 1 for a generic individual are:

$\mathrm{dA}_{1} / \mathrm{dt}=-\mathrm{k}_{12} \mathrm{~A}_{1}$

$\mathrm{C}_{\mathrm{z}}=\mathrm{k}_{12} \mathrm{~A}_{1}+\mathrm{Q}_{1} \mathrm{C}_{2} /\left(\mathrm{Q}_{1}+\mathrm{CL}_{23}\right)$

$\mathrm{dA}_{2} / \mathrm{dt}=\mathrm{Q}_{1} \mathrm{C}_{\mathrm{z}}-\mathrm{Q}_{1} \mathrm{C}_{2}-\mathrm{Q}_{2} \mathrm{C}_{2}+\mathrm{Q}_{2} \mathrm{C}_{6}-\mathrm{CL}_{24} \mathrm{C}_{2}$

$\mathrm{dA}_{3} / \mathrm{dt}=\mathrm{CL}_{23} \mathrm{C}_{\mathrm{z}}-\mathrm{CL}_{30} \mathrm{C}_{3}-\mathrm{CL}_{35} \mathrm{C}_{3}$

$\mathrm{dA}_{4} / \mathrm{dt}=\mathrm{CL} 24 \mathrm{C} 2$

$\mathrm{dA}_{5} / \mathrm{dt}=\mathrm{CL}_{24} \mathrm{C}_{2}$

$\mathrm{dA}_{6} / \mathrm{dt}=\mathrm{Q}_{2} \mathrm{C}_{2}-\mathrm{Q}_{2} \mathrm{C}_{6}$

The differential equation for the hypothetical enzyme compartment can be written as follows:

$\mathrm{dC}_{\mathrm{z}} / \mathrm{dt}=\mathrm{k}_{12} \mathrm{~A}_{1}+\mathrm{Q} 1 \mathrm{C}_{2}-\mathrm{Q}_{1} \mathrm{C}_{\mathrm{z}}-\mathrm{CL}_{23} \mathrm{C}_{\mathrm{z}}$

where $\mathrm{C}_{\mathrm{z}}$ is the concentration in the metabolizing compartment. The model assumes rapid equilibrium between this compartment and the DM central compartment.

$0=\mathrm{k}_{12} \mathrm{~A}_{1}+\mathrm{Q}_{1} \mathrm{C}_{2}-\left(\mathrm{Q}_{1}+\mathrm{CL}_{23}\right) \mathrm{C}_{\mathrm{z}}$

This equation can be rearranged to get the following expression for $\mathrm{C}_{z}$

$\mathrm{C}_{\mathrm{z}}=\mathrm{k}_{12} \mathrm{~A}_{1}+\mathrm{Q}_{1} \mathrm{C}_{2} /\left(\mathrm{Q}_{1}+\mathrm{CL}_{23}\right)$

The differential expression for DM in the central compartment $\left(\mathrm{A}_{2}\right)$ is:

$\mathrm{dA}_{2} / \mathrm{dt}=\mathrm{Q}_{1} \mathrm{C}_{\mathrm{z}}-\mathrm{Q}_{1} \mathrm{C}_{2}-\mathrm{Q}_{2} \mathrm{C}_{2}+\mathrm{Q}_{2} \mathrm{C}_{6}-\mathrm{CL}_{24} \mathrm{C}_{2}$

After substituting $\mathrm{C}_{\mathrm{z}}$

$\mathrm{dA}_{2} / \mathrm{dt}=\mathrm{Q}_{1}\left(\mathrm{k}_{12} \mathrm{~A}_{1}+\mathrm{Q}_{1} \mathrm{C}_{2} /\left(\mathrm{Q}_{1}+\mathrm{CL}_{23}\right)\right)-\mathrm{Q}_{1} \mathrm{C}_{2}-\mathrm{Q}_{2} \mathrm{C}_{2}+\mathrm{Q}_{2} \mathrm{C}_{6}-\mathrm{CL}_{24} \mathrm{C}_{2}$

Similarly for the DO plasma compartment:

$\mathrm{dA}_{3} / \mathrm{dt}=\mathrm{CL}_{23} \mathrm{C}_{\mathrm{z}}-\mathrm{CL}_{30} \mathrm{C}_{3}-\mathrm{CL}_{35} \mathrm{C}_{3}$

After substituting $\mathrm{C}_{\mathrm{Z}}$ :

$\mathrm{dA}_{3} / \mathrm{dt}=\mathrm{CL}_{23}\left(\left(\mathrm{k}_{12} \mathrm{~A}_{1}+\mathrm{Q}_{1} \mathrm{C}_{2}\right) /\left(\mathrm{Q}_{1}+\mathrm{CL}_{23}\right)\right)-\mathrm{CL}_{30} \mathrm{C}_{3}-\mathrm{CL}_{35} \mathrm{C}_{3}$

where $A_{i}$ and $C_{i}$ denote the amount and concentration of the species associated with the $i^{\text {th }}$ compartment in Figure 1. 


\section{Figure Legends}

Figure 1 Blueprint of the final semi-mechanistic population model of dextromethorphan (DM) and dextrorphan (DO) in plasma and urine after administration of single oral doses of $30 \mathrm{mg}$ DM hydrobromide. The absorption phase is described with a rate constant (ka) and lag time ( $\mathrm{t}_{\mathrm{lag}}$ ). $\mathrm{C}_{\mathrm{p}}$ and $\mathrm{C}_{\mathrm{u}}$ are plasma and urine concentration of DM or DO in the corresponding compartments. $\mathrm{C}_{\mathrm{z}}$ is the concentration of $\mathrm{DM}$ in the hypothetical metabolizing enzyme compartment, which is in rapid equilibration with that in plasma $\left(C_{p}\right) . Q_{1}$ is the intercompartmental clearance between the central compartment of DM and the metabolizing enzyme compartment. $\mathrm{CL}_{23}$ is the apparent systemic metabolic clearance of DM to DO, which is the sum of the basic $\left(\mathrm{CL}_{\mathrm{b}}\right)$ and CYP2D6-mediated $\left(\mathrm{CL}_{\mathrm{CYP} 2 \mathrm{D} 6}\right)$ components. $\mathrm{Q}_{2}$ is the intercompartmental clearance between central and peripheral compartments of $\mathrm{DM}, \mathrm{CL}_{24}$ is the renal clearance of DM under the influence of urine $\mathrm{pH}(\mathrm{UpH}), \mathrm{CL}_{35}$ represents $\mathrm{DO}$ renal clearance, and $\mathrm{CL}_{30}$ is the clearance of DO to other species.

Figure 2 Goodness-of-fit plots for the final model; a Goodness-of-fit plots for plasma concentrations of dextromethorphan (left) and dextrorphan (right); b Goodness-of-fit plots for amounts excreted in urine of dextromethorphan (left) and dextrorphan (right).

Figure 3 Visual predictive check plots showing adequacy of the developed model to describe the actual data (filled black circles=dextromethorphan data, unfilled circles $=$ dextrorphan) as they are almost equally dispersed on the both side of simulated median $\left(50^{\text {th }}\right.$ percentile $)$. Plasma observations are shown on the upper panel.

Figure 4 Simulated typical time courses in plasma (upper panel) and urine (lower panel) for individuals with different genotypes. 


\section{References}

(1) Moghadamnia, A.A., Rostami-Hodjegan, A., Abdul-Manap, R., Wright, C.E., Morice, A.H. \& Tucker, G.T. Physiologically based modelling of inhibition of metabolism and assessment of the relative potency of drug and metabolite: dextromethorphan vs. dextrorphan using quinidine inhibition. Br J Clin Pharmacol 56, 57-67 (2003).

(2) Capon, D.A., Bochner, F., Kerry, N., Mikus, G., Danz, C. \& Somogyi, A.A. The influence of CYP2D6 polymorphism and quinidine on the disposition and antitussive effect of dextromethorphan in humans. Clin Pharmacol Ther 60, 295-307 (1996).

(3) Borges, S., Li, L., Hamman, M.A., Jones, D.R., Hall, S.D. \& Gorski, J.C. Dextromethorphan to dextrorphan urinary metabolic ratio does not reflect dextromethorphan oral clearance. Drug Metab Dispos 33, 1052-5 (2005).

(4) Jacqz-Aigrain, E., Funck-Brentano, C. \& Cresteil, T. CYP2D6- and CYP3Adependent metabolism of dextromethorphan in humans. Pharmacogenetics 3, 197204 (1993).

(5) Barnhart, J.W. The urinary excretion of dextromethorphan and three metabolites in dogs and humans. Toxicol Appl Pharmacol 55, 43-8 (1980).

(6) Chladek, J., Zimova, G., Beranek, M. \& Martinkova, J. In-vivo indices of CYP2D6 activity: comparison of dextromethorphan metabolic ratios in 4-h urine and 3-h plasma. Eur J Clin Pharmacol 56, 651-7 (2000).

(7) Frank, D., Jaehde, U. \& Fuhr, U. Evaluation of probe drugs and pharmacokinetic metrics for CYP2D6 phenotyping. Eur J Clin Pharmacol 63, 321-33 (2007).

(8) Gaedigk, A., Simon, S.D., Pearce, R.E., Bradford, L.D., Kennedy, M.J. \& Leeder, J.S. The CYP2D6 activity score: translating genotype information into a qualitative measure of phenotype. Clin Pharmacol Ther 83, 234-42 (2008).

(9) Gaedigk, A., Bradford, L.D., Marcucci, K.A. \& Leeder, J.S. Unique CYP2D6 activity distribution and genotype-phenotype discordance in black Americans. Clin Pharmacol Ther 72, 76-89 (2002).

(10) Laika, B., Leucht, S., Heres, S. \& Steimer, W. Intermediate metabolizer: increased side effects in psychoactive drug therapy. The key to cost-effectiveness of pretreatment CYP2D6 screening? Pharmacogenomics $J$ 9, 395-403 (2009).

(11) Kirchheiner, J., Nickchen, K., Bauer, M., Wong, M.L., Licinio, J., Roots, I. \& Brockmoller, J. Pharmacogenetics of antidepressants and antipsychotics: the contribution of allelic variations to the phenotype of drug response. Mol Psychiatry 9, 442-73 (2004).

(12) Kirchheiner, J., Keulen, J.T., Bauer, S., Roots, I. \& Brockmoller, J. Effects of the CYP2D6 gene duplication on the pharmacokinetics and pharmacodynamics of tramadol. J Clin Psychopharmacol 28, 78-83 (2008).

(13) Kirchheiner, J., Schmidt, H., Tzvetkov, M., Keulen, J.T., Lotsch, J., Roots, I. \& Brockmoller, J. Pharmacokinetics of codeine and its metabolite morphine in ultra- 
rapid metabolizers due to CYP2D6 duplication. Pharmacogenomics $J$ 7, 257-65 (2007).

(14) Kirchheiner, J., Brosen, K., Dahl, M.L., Gram, L.F., Kasper, S., Roots, I., Sjoqvist, F., Spina, E. \& Brockmoller, J. CYP2D6 and CYP2C19 genotype-based dose recommendations for antidepressants: a first step towards subpopulation-specific dosages. Acta Psychiatr Scand 104, 173-92 (2001).

(15) Schmid, B., Bircher, J., Preisig, R. \& Kupfer, A. Polymorphic dextromethorphan metabolism: co-segregation of oxidative O-demethylation with debrisoquin hydroxylation. Clin Pharmacol Ther 38, 618-24 (1985).

(16) Bock, K.W., Schrenk, D., Forster, A., Griese, E.U., Morike, K., Brockmeier, D. \& Eichelbaum, M. The influence of environmental and genetic factors on CYP2D6, CYP1A2 and UDP-glucuronosyltransferases in man using sparteine, caffeine, and paracetamol as probes. Pharmacogenetics 4, 209-18 (1994).

(17) Sachse, C., Brockmoller, J., Bauer, S. \& Roots, I. Cytochrome P450 2D6 variants in a Caucasian population: allele frequencies and phenotypic consequences. Am J Hum Genet 60, 284-95 (1997).

(18) Steimer, W., Zopf, K., von Amelunxen, S., Pfeiffer, H., Bachofer, J., Popp, J., Messner, B., Kissling, W. \& Leucht, S. Allele-specific change of concentration and functional gene dose for the prediction of steady-state serum concentrations of amitriptyline and nortriptyline in CYP2C19 and CYP2D6 extensive and intermediate metabolizers. Clin Chem 50, 1623-33 (2004).

(19) Piotrovskij, V., Van Peer, A. A model with separate hepato-portal compartment ("first-pass" model): fitting to plasma concentration-time profiles in humans. Pharm Res 14, 230-7 (1997).

(20) Levi, M., Dempsey, D.A., Benowitz, N.L. \& Sheiner, L.B. Population pharmacokinetics of nicotine and its metabolites I. Model development. $J$ Pharmacokinet Pharmacodyn 34, 5-21 (2007).

(21) Florence, A.T. \& Attwood, D. Physicochemical principles of pharmacy, 4th ed., Pharmaceuitcal Press, London, UK., (2006).

(22) Costache, A.D., Trawick, D., Bohl, D. \& Sem, D.S. AmineDB: large scale docking of amines with CYP2D6 and scoring for druglike properties--towards defining the scope of the chemical defense against foreign amines in humans. Xenobiotica 37, 221-45 (2007).

(23) Gotoh, O. Substrate recognition sites in cytochrome P450 family 2 (CYP2) proteins inferred from comparative analyses of amino acid and coding nucleotide sequences. $J$ Biol Chem 267, 83-90 (1992).

(24) Yu, A., Kneller, B.M., Rettie, A.E. \& Haining, R.L. Expression, purification, biochemical characterization, and comparative function of human cytochrome P450 2D6.1, 2D6.2, 2D6.10, and 2D6.17 allelic isoforms. J Pharmacol Exp Ther 303, 1291-300 (2002).

(25) Jiang, X.L., Shen, H.W. \& Yu, A.M. Pinoline may be used as a probe for CYP2D6 activity. Drug Metab Dispos 37, 443-6 (2009). 
(26) Niwa, T., Hiroi, T., Tsuzuki, D., Yamamoto, S., Narimatsu, S., Fukuda, T., Azuma, J. \& Funae, Y. Effect of genetic polymorphism on the metabolism of endogenous neuroactive substances, progesterone and p-tyramine, catalyzed by CYP2D6. Brain Res Mol Brain Res 129, 117-23 (2004).

(27) Bapiro, T.E., Hasler, J.A., Ridderstrom, M. \& Masimirembwa, C.M. The molecular and enzyme kinetic basis for the diminished activity of the cytochrome P450 2D6.17 (CYP2D6.17) variant. Potential implications for CYP2D6 phenotyping studies and the clinical use of CYP2D6 substrate drugs in some African populations. Biochem Pharmacol 64, 1387-98 (2002).

(28) Marcucci, K.A., Pearce, R.E., Crespi, C., Steimel, D.T., Leeder, J.S. \& Gaedigk, A. Characterization of cytochrome P450 2D6.1 (CYP2D6.1), CYP2D6.2, and CYP2D6.17 activities toward model CYP2D6 substrates dextromethorphan, bufuralol, and debrisoquine. Drug Metab Dispos 30, 595-601 (2002).

(29) Hallifax, D. \& Houston, J.B. Methodological uncertainty in quantitative prediction of human hepatic clearance from in vitro experimental systems. Curr Drug Metab 10, 307-21 (2009).

(30) Panserat, S., Sica, L., Gerard, N., Mathieu, H., Jacqz-Aigrain, E. \& Krishnamoorthy, R. CYP2D6 polymorphism in a Gabonese population: contribution of the CYP2D6*2 and CYP2D6*17 alleles to the high prevalence of the intermediate metabolic phenotype. Br J Clin Pharmacol 47, 121-4 (1999).

(31) Toscano, C., Klein, K., Blievernicht, J., Schaeffeler, E., Saussele, T., Raimundo, S., Eichelbaum, M., Schwab, M. \& Zanger, U.M. Impaired expression of CYP2D6 in intermediate metabolizers carrying the $* 41$ allele caused by the intronic SNP 2988G $>$ A: evidence for modulation of splicing events. Pharmacogenet Genomics 16, 755-66 (2006).

(32) Raimundo, S., Toscano, C., Klein, K., Fischer, J., Griese, E.U., Eichelbaum, M., Schwab, M. \& Zanger, U.M. A novel intronic mutation, 2988G $>$ A, with high predictivity for impaired function of cytochrome P450 2D6 in white subjects. Clin Pharmacol Ther 76, 128-38 (2004).

(33) Kusama, M., Maeda, K., Chiba, K., Aoyama, A. \& Sugiyama, Y. Prediction of the effects of genetic polymorphism on the pharmacokinetics of CYP2C9 substrates from in vitro data. Pharm Res 26, 822-35 (2009).

(34) Shen, H., He, M.M., Liu, H., Wrighton, S.A., Wang, L., Guo, B. \& Li, C. Comparative metabolic capabilities and inhibitory profiles of CYP2D6.1, CYP2D6.10, and CYP2D6.17. Drug Metab Dispos 35, 1292-300 (2007).

(35) Duedahl, T.H., Dirks, J., Petersen, K.B., Romsing, J., Larsen, N.E. \& Dahl, J.B. Intravenous dextromethorphan to human volunteers: relationship between pharmacokinetics and anti-hyperalgesic effect. Pain 113, 360-8 (2005).

(36) Silvasti, M., Karttunen, P., Tukiainen, H., Kokkonen, P., Hanninen, U. \& Nykanen, S. Pharmacokinetics of dextromethorphan and dextrorphan: a single dose comparison of three preparations in human volunteers. Int J Clin Pharmacol Ther Toxicol 25, 493-7 (1987). 
(37) Albers, G.W., Atkinson, R.P., Kelley, R.E. \& Rosenbaum, D.M. Safety, tolerability, and pharmacokinetics of the N-methyl-D-aspartate antagonist dextrorphan in patients with acute stroke. Dextrorphan Study Group. Stroke 26, 254-8 (1995).

(38) Demirbas, S., Reyderman, L. \& Stavchansky, S. Bioavailability of dextromethorphan (as dextrorphan) from sustained release formulations in the presence of guaifenesin in human volunteers. Biopharm Drug Dispos 19, 541-5 (1998).

(39) Labbe, L., Sirois, C., Pilote, S., Arseneault, M., Robitaille, N.M., Turgeon, J. \& Hamelin, B.A. Effect of gender, sex hormones, time variables and physiological urinary $\mathrm{pH}$ on apparent CYP2D6 activity as assessed by metabolic ratios of marker substrates. Pharmacogenetics 10, 425-38 (2000).

(40) Fuhr, U. Pharmacogenetic-based clinical scores: a useful, simple tool to predict tamoxifen-based CYP2D6 phenotype? J Clin Pharmacol 50, 370-2 (2010).

(41) Klaassen, T., Jetter, A., Tomalik-Scharte, D., Kasel, D., Kirchheiner, J., Jaehde, U. \& Fuhr, U. Assessment of urinary mephenytoin metrics to phenotype for CYP2C19 and CYP2B6 activity. Eur J Clin Pharmacol 64, 387-98 (2008).

(42) Tomalik-Scharte, D., Lutjohann, D., Doroshyenko, O., Frank, D., Jetter, A. \& Fuhr, U. Plasma 4beta-hydroxycholesterol: an endogenous CYP3A metric? Clin Pharmacol Ther 86, 147-53 (2009).

(43) Wyen, C., Fuhr, U., Frank, D., Aarnoutse, R.E., Klaassen, T., Lazar, A., Seeringer, A., Doroshyenko, O., Kirchheiner, J.C., Abdulrazik, F., Schmeisser, N., Lehmann, C., Hein, W., Schomig, E., Burger, D.M., Fatkenheuer, G. \& Jetter, A. Effect of an antiretroviral regimen containing ritonavir boosted lopinavir on intestinal and hepatic CYP3A, CYP2D6 and P-glycoprotein in HIV-infected patients. Clin Pharmacol Ther 84, 75-82 (2008).

(44) Gaedigk, A., Ndjountche, L., Divakaran, K., Dianne Bradford, L., Zineh, I., Oberlander, T.F., Brousseau, D.C., McCarver, D.G., Johnson, J.A., Alander, S.W., Wayne Riggs, K. \& Steven Leeder, J. Cytochrome P4502D6 (CYP2D6) gene locus heterogeneity: characterization of gene duplication events. Clin Pharmacol Ther 81, 242-51 (2007).

(45) Holford, N. Input-output models. In: Kimko HC, Duffull SB, eds. Simulation for Designing Clinical Trials: A Pharmacokinetic-Pharmacodynamic Perspective. Vol 125 New York, NY: Marcel Dekker, Pp 2-31, (2002). 


\section{Tables}

Table 1 Demographic data given as mean \pm standard deviation (range).

\begin{tabular}{ccccc}
\hline \multirow{2}{*}{ Characteristics } & \multicolumn{5}{c}{ Values } \\
\cline { 2 - 5 } & Study A & Study B & Study C & Total \\
\hline $\begin{array}{c}\text { Number of subjects } \\
\text { used in the evaluation }\end{array}$ & $\mathbf{1 5}$ & $\mathbf{1 0}$ & $\mathbf{1 1}$ & \multirow{2}{*}{36} \\
\hline Age (years) & $28.5 \pm 4.70$ & $29.6 \pm 6.5$ & $30.5 \pm 9.6$ & $29.4 \pm 6.85$ \\
& $(23-38)$ & $(22-43)$ & $(18-48)$ & $(18-49)$ \\
\hline Body weight $(\mathrm{kg})$ & $78.1 \pm 10.1$ & $79.5 \pm 9.2$ & $71.7 \pm 5.3$ & $76.5 \pm 9.01$ \\
& $(65-101.1)$ & $(66.3-92)$ & $(82-60)$ & $(60-101)$ \\
\hline Height $(\mathrm{cm})$ & $182.3 \pm 7.0$ & $180.1 \pm 6.4$ & $180.6 \pm 5.8$ & $181.3 \pm 6.38$ \\
& $(171-195)$ & $(173-194)$ & $(171-190)$ & $(171-195)$ \\
\hline
\end{tabular}


Table 2 Genotypes of individuals from the three clinical studies used in this evaluation.

\begin{tabular}{|c|c|c|c|c|}
\hline $\begin{array}{l}\text { CYP2D6 } \\
\text { genotype }\end{array}$ & Study A & Study B & Study C & Total \\
\hline$* 1 / * 1$ & 2 & 3 & 1 & 6 \\
\hline$* 1 / * 2$ & 2 & 0 & 2 & 4 \\
\hline$* 1 / * 4$ & 6 & 1 & 0 & 7 \\
\hline$* 1 / * 41$ & 1 & 3 & 1 & 5 \\
\hline$* 4 / * 4$ & 1 & 0 & 0 & 1 \\
\hline$* 2 / * 4$ & 1 & 0 & 3 & 4 \\
\hline$* 2 / * 41$ & 0 & 0 & 1 & 1 \\
\hline$* 4 / * 41$ & 0 & 1 & 0 & 1 \\
\hline$* 1 \times 2 / * 2$ & 1 & 0 & 0 & 1 \\
\hline$* 1 / * 1 \times 2$ & 0 & 1 & 0 & 1 \\
\hline$* 2 / * 2 \times 2$ & 1 & 0 & 0 & 1 \\
\hline$* 2 \times 2 / * 3$ & 0 & 1 & 0 & 1 \\
\hline$* 2 / * 2$ & 0 & 0 & 2 & 2 \\
\hline$* 2 / * 4 \times 2$ & 0 & 0 & 1 & 1 \\
\hline
\end{tabular}


Table 3 Pharmacokinetic parameter estimates for the population

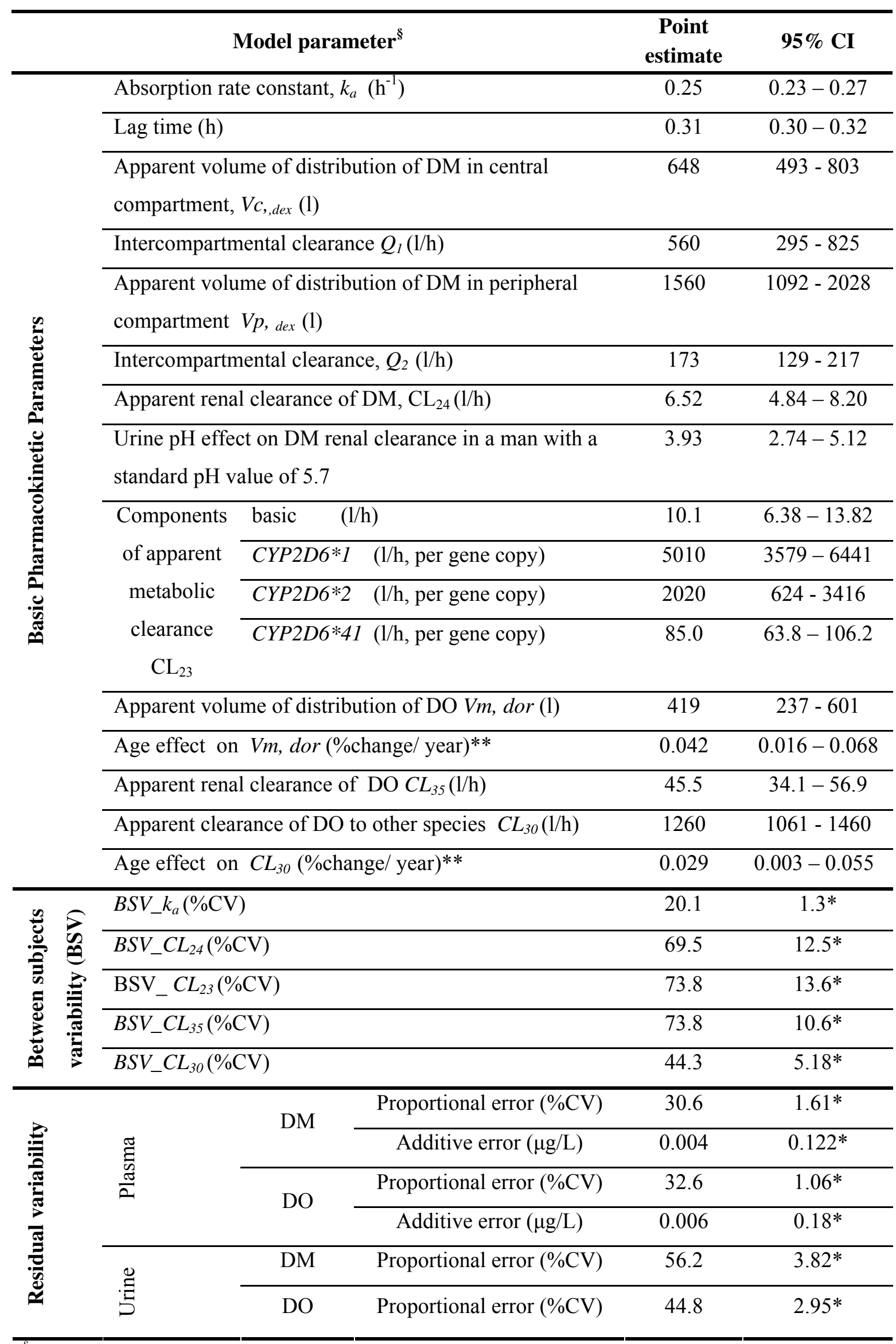

${ }^{\S}$ see Fig. 1 for individual parameters; $*=$ percentage of relative standard error

** centered around 27 years 